\title{
BARTHES DESDE ESTA ORILLA: EL ESCRUTINIO DE MARTÍN CERDA
}

\author{
Barthes from this shore: Martin Cerda scrutiny
}

Ismael Gavilán*

\section{RESUMEN}

Hay escritores que en un campo literario son fundamentales para explorar nuevos territorios: traducen y comunican lo fundamental de tendencias y autores aun no conocidos y ejercen un magisterio desde la escritura para forjar una opinión informada. En aquel sentido, la temprana recepción de la obra de Roland Barthes por parte de Martín Cerda es primordial e ineludible pues forma parte medular de su propia manera de entender y practicar la escritura ensayística. Esta recepción es para Cerda la posibilidad de hallar una salida expresiva que esté equidistante entre las obsesiones subjetivas y la curiosidad que lo real puede ofrecer al intelecto escrutador que posee todo escritor.

Palabras clave: Traducción, interpretación, escritura, ensayo, crítica literaria.

\begin{abstract}
There are writers in a literary field are essential to explore new territory: translate and communicate the essentials of trends and yet unknown authors and exercise teachers from writing to build an informed opinion. In that sense, the early reception of the work of Roland Barthes by Martin Cerda is essential and unavoidable because it forms a core part of their own way of understanding and practicing essay writing. This reception is to sow the possibility of finding an expressive outlet that is equidistant between subjective obsessions and curiosity that reality can offer the teller intellect has every writer.
\end{abstract}

Keywords: Translation, interpretation, writing, essay, literary criticism.

* Instituto de Literatura, Universidad de Los Andes. Santiago, Chile. Correo electrónico: igavilan2@ gmail.com

Artículo recibido el 28 de julio de 2014. Aceptado el 23 de enero de 2015. 
Resulta aleccionador, en lo que a literatura hispanoamericana se refiere, efectuar un ejercicio imaginativo de lectura cuando volvemos la mirada a los años cincuenta del siglo XX. En una enumeración caótica que no pretende ser exhaustiva, aparecen una serie de nombres, eventos, libros y acciones que, sin duda, han contribuido a diagramar la imagen que tenemos de nosotros mismos como habitantes de una ciudad letrada en pleno proceso de transformación. Así, a mediados del siglo recién pasado, esa imagen estaba en pleno auge y proceso para configurarse a sí misma y, aun más, para consolidarse soberana. En una acelerada modernización, producto de las consecuencias ocasionadas por el fin de la Segunda Guerra Mundial y que trajeron, entre otras, una política desarrollista que afectó todas las capas sociales y productivas del continente (Hopenhayn, 2004), como asimismo la emergencia renovada de un espíritu utópico basado en la lección de esos maestros ejemplares que fueron Pedro Henríquez Ureña, Alfonso Reyes, Ezequiel Martínez Estrada y José Carlos Mariátegui (Mariaca, 2007; Parra, 2013), no es redundante afirmar que la mitad del siglo recién pasado fue campo fértil, no solo para intentar responder e indagar las interrogantes en torno a la identidad latinoamericana que venían plasmándose desde el siglo anterior, sino también, era un tiempo estimulante para, al interior de esa misma actitud cavilosa, levantar la mirada desde nosotros mismos hacia Europa y Norteamérica, para volverla diferente, crítica y autocrítica, en un gesto reflexivo y abierto al mundo que ya Martí y Darío habían anunciado hacía más de cincuenta años atrás.

Es en el transcurso de esa década, por ejemplo, donde ven la luz dos de los más importantes libros de la extensa bibliografía de Octavio Paz: El laberinto de la soledad, (1950) y El Arco y la Lira (1956) donde la pregunta por la identidad va acompañada por la reflexión acerca de la poesía y sus posibilidades. Es la década que ve también el arribo de un crítico y ensayista magistral como lo fue Ángel Rama al comité de redacción del ya célebre semanario uruguayo Marcha, arribo que le otorgará a esa publicación aquella fisonomía editorial que la hará única en el imaginario intelectual latinoamericano de la segunda mitad del siglo. Son los años en que Jorge Luis Borges, después de publicar El Aleph, publica Otras Inquisiciones (1952), sumergiéndonos en la peculiaridad de su laberinto imaginativo lleno de paradojas y visiones deslumbrantes, ańos en que, de modo casi paralelo, Ernesto Sábato publica Hombres y engranajes (1951) como una forma vasta y profunda de reflexionar acerca de los avatares de la ciencia y el humanismo occidental desde su personal observatorio bonaerense. Son los años en que Julio Cortázar en una sucesión milagrosa da a luz Bestiario (1951), Final de Juego (1956) y Las armas secretas (1959), títulos sin los cuales no podríamos entender el arte del relato en la singularidad de nuestro idioma y nuestra imaginación. Es también la década en que José Lezama Lima nos regala con lo más granado de su alucinante prosa ensayística: Analecta del reloj (1953), La expresión americana (1957) y Tratados en 
La Habana (1958) y donde advertimos que lucidez y análisis no son antónimos de juego, arbitrariedad y gratuidad metafórica. Década que también acoge aquel milagro que son El llano en llamas (1953) y Pedro Páramo (1955) de Juan Rulfo, donde la memoria, el silencio y la inocencia nos entregan casi una experiencia física de anonadamiento. Pero es también la década que ve aparecer los primeros libros de Juan García Ponce como El canto de los grillos (1958), los primeros y polémicos ensayos teñidos de fenomenología y psicoanálisis de Oscar Masotta sobre Sartre y Merleau-Ponty, década que ve la escritura y publicación de los primeros cuentos de Mario Vargas Llosa como asimismo la aparición de aquel insuperable y mal comprendido ensayo de Héctor Murena El pecado original de América (1954).

Viendo -y rememorando en la soledad de la lectura- esas obras que señalo, vale la pena volver la mirada sobre nuestra propia parcela ¿Qué sucedía a mediados de las años 50 en la literatura chilena? ¿Cuáles eran las preocupaciones estéticas y literarias de nuestro campo cultural? Por supuesto que no pretendo agotar aquí las posibles respuestas a tamañas preguntas. Pero creo que no tenemos que ser historiadores exhaustivos para informarnos de las acciones de aquel acontecer. Tal vez hoy, en un mundo interconectado y con información simultánea acerca de lo que sucede y acaece en el campo literario nacional e internacional, cuesta imaginarnos sesenta años después, lo que movía las pasiones de nuestra ciudad letrada. Pero ese costo no es impedimento para llevar acabo un breve ejercicio ejemplar.

Si efectuamos una mirada retrospectiva, a mediados de la década del 50, para ser más específicos, en junio de 1954, se llevó a cabo en el Salón de Honor de la Universidad de Chile, un ciclo de conferencias donde participaron los escritores y críticos Ernesto Montenegro, Manuel Vega y Ricardo Latcham. El título de tal ciclo era decidor: La querella del criollismo. El tema principal era la reevaluación del criollismo para el desarrollo de la literatura nacional y de la hispanoamericana en su conjunto. Sin duda, uno de sus objetivos era mirar en perspectiva la historia de esta corriente literaria para darle fondo y alcance geográfico e histórico y así, considerar sus manifestaciones al interior de la literatura chilena, como asimismo, sus características comunes con otras literaturas del resto del continente y las consecuencias estéticas, políticas y sociales que se esperaban de su cultivo (Bernaschina y Soto, 2011). Transcurridas algunas semanas de tal evento, el crítico Hernán Díaz Arrieta (Alone), publicaba en la revista Zig-Zag un artículo titulado escuetamente "La querella del criollismo: Montaña Adentro" con el cual daba inicio a una polémica que lo tendría a él mismo y a Ricardo Latcham entre los principales protagonistas. No era la primera vez que Alone y Latcham medían sus fuerzas críticas -y valga decir, sus respectivas retóricas- en la arena de la ciudad letrada chilena. $\mathrm{Ni}$ tampoco era la primera vez que el criollismo como corriente literaria era puesta en entredicho. Ya en 1928, la denominada querella 
entre criollistas e imaginistas, revelaba más que una pugna entre escritores -por un lado Mariano Latorre, Marta Brunet, Eduardo Barrios y por otro Salvador Reyes y Luis Enrique Délano- en torno a los mejores "temas" y modos de abordar el tratamiento del ejercicio narrativo, sino más bien revelaba una coyuntura más vasta: la crisis nacional y social que surgió alrededor del primer Centenario de la República y cuyas características han sido descritas con acuciosidad, entre otros, por los trabajos de Bernardo Subercaseux (2010). Sin pecar de excesivo, podríamos resumir que en las primeras décadas del siglo XX asistimos a una complejización del imaginario nacional, producto de una tensión entre postulados e impulsos nacionalistas y modernizadores, donde la paulatina desintegración de la sociedad tradicional decimonónica, el crecimiento de las ciudades, la explotación laboral y la emergencia de nuevas capas sociales y, por ende, la reorganización de aspectos fundamentales de la vida cotidiana, junto a otras variables y situaciones, permitían advertir, en el campo literario chileno, una mezcla de prerrogativas sociales e identitarias, entre nacionalismo y modernización, donde expresiones tales como patria, raza y paisaje, se contraponían, entre otros, a imaginación, sensibilidad y buen gusto (2010).

Lo que la querella de 1954 ejemplificaba simbólicamente en las premisas sostenidas por Latcham y Alone, más que la superación de aquellas dicotomías, era la pugna por representar del mejor modo posible el "deber ser" del discurso literario respecto a su función en el entramado social y cultural y que, de todas formas, implicaba plantear la relación y estatus que el discurso literario mantenía respecto de la realidad. Y si bien, ambas premisas parecían referirse una a la otra de modo antagónico para responder sobre aquella necesidad, coincidían a la larga en hacer del ejercicio literario, un ejercicio mimético que apelaba ya a la exterioridad del sujeto con un énfasis en la descripción y estudio minucioso de la realidad nacional en todos sus aspectos, para reproducirla en obras que permitieran dar a conocer y enseñar a sus lectores de forma objetiva la verdad sobre la nación y la raza ya, por otro lado, apelaba a su interioridad -con un énfasis en ser fiel representación de la sensibilidad, el espíritu, la imaginación y el alma con un fuerte acento intimista-. En ese sentido, más que abrir un camino hacia una literatura acorde a los procesos modernizadores que acontecían en el país y en el resto de América Latina, procesos que la misma corriente criollista, paradójicamente, revindicaba en su afán identitario, lo que podía apreciarse era una comprensión depediente de lo literario, pero sobre todo, una comprensión enraizada en un concepto decimonónico de literatura (Bernaschina y Soto, 2011).

Todo lo dicho hasta aquí no es más que preámbulo, pero nos permite escenificar de forma irónica la disonancia entre las preocupaciones existentes en el desfasado campo literario chileno de mediados de los años 50 y las premisas que animaban lo más relevante de la literatura continental, no tanto o en exclusiva 
restringido a temas y convenciones de escritura, sino más bien sobre la idea que se podía desprender acerca del sentido y finalidad de la literatura respecto de sus mecanismos de representación y el modo de asumirse en tanto escritura.

En aquel debate, suena a ciencia ficción conjeturar hoy en día la resonancia que hubiese tenido la eventual publicación de El grado cero de la escritura de Roland Barthes en la traducción de Martín Cerda que, justamente, luego de su periplo europeo, arribó a Chile poco antes de que estallara la polémica a la que acabo de referirme. Es que, ciertamente, el caso de Cerda respecto a Barthes, no solo es singular y excéntrico: es medular tanto para el entendimiento que podamos hacer de la obra ensayística del propio Cerda como para apreciar los avatares de la recepción de Barthes en nuestro país.

Es indudable que hay escritores que en un campo literario determinado son fundamentales para explorar nuevos territorios: traen noticia de lo que se está fraguando en otros rincones del mundo, traducen lo fundamental de tendencias y autores aun no conocidos y ejercen un magisterio desde la escritura para forjar una opinión informada y veraz a través de la columna de opinión, el artículo, la reseña o el ensayo.

En este sentido, a partir de mediados de los años 50 y hasta el final de su vida, Martín Cerda fue uno de los más relevantes escritores que con dedicación, celo y entusiasmo leyó, parafraseó, divulgó y explicó una serie de nombres que el mundillo literario chileno no conocía o mal había oído. El dato ejemplificador que enunciaba acerca de la querella del criollismo muestra a mi modo de ver, la asimetría desquiciante, asimetría ante la cual Cerda veía la necesidad quijotesca de traducir al castellano El grado cero de la escritura o El dios cautivo de Lucien Goldmann.

Pero no se trata de constatar el interés de Cerda por esos autores como por otros de su predilección como Lukács, Axelos y Solyenitsin como manifestación de un esnobismo intelectual, teñido de cierta ingenuidad provinciana, sino más bien de apreciar en aquel interés, una necesidad vital por buscar respuestas a las lacerantes preguntas que cualquier escritor que se precie se plantea acerca de sí mismo y su labor: ¿Por qué escribir? ¿Para quién escribir? ¿Con qué sentido escribir? Preguntas sin respuesta inmediata y que, el joven Cerda intentó responder viajando muy temprano a Europa a fines de los años 40 y con la idea de dar oportunidad, no solo a su natural curiosidad intelectual, sino a su exigencia íntima de escritor en ciernes. Porque no solo se trataba de lecturas, datos eruditos o experiencias de viaje, se trataba de concientizar un rigor, una intensidad, una actitud hacia la escritura lo suficientemente decidida para comprometerse con ella a sabiendas de la indiferencia social y la chatura de la época, un verdadero desafío para aprender a pensar.

Para lograr ese aprendizaje, múltiples son las puertas entreabiertas por las lecturas de Cerda, no todas valoradas en su justa medida en su oportunidad, 
tal como puede verse en su temprana recepción de Barthes, pero decidoras al momento de plantearse como desafío de una literatura que se querría a sí misma como pensante y cuestionadora. La recepción de Barthes por parte de Cerda, con el correr de los años, se vuelve primordial e ineludible, formando parte medular de su propia manera de entender y practicar la escritura ensayística. Junto a Lukács y Ortega, Barthes es para Cerda la posibilidad de hallar una salida expresiva que esté equidistante entre las obsesiones subjetivas y la curiosidad que lo real puede ofrecer al intelecto escrutador de todo escritor.

Las referencias, citas, paráfrasis, explicaciones y alusiones a Barthes atraviesan buena parte de la escritura de Cerda, al menos de la que hasta ahora tenemos noticia ${ }^{1}$. En tamaño océano escrito, es difícil dilucidar fehacientemente los detalles de esta apasionante relación. En esta oportunidad, me limitaré a esbozar tres instantes que creo advertir en la recepción de Cerda y de qué modo cada una de ellas articula maneras de reflexión peculiares según la ocasión. Estos tres instantes no son necesariamente cronológicos, apuntan más bien a una modulación de amplio espectro que surca de manera intensa la prosa ensayística del autor de Escritorio.

En primer término es posible apreciar que para Cerda, Barthes se convierte en una especie de "marco referencial" para poder comprender el discurso literario no como historia o sucesión de estilos, ni de avatares o acumulación de eventos que condicionan lo literario, sino que le facilita coordenadas para dilucidar desde dónde escribir: el acontecimiento supremo que es la escritura y que se rinde ante sí misma en su opacidad que desea diferenciarse de la historia, pero sin renunciar a la posibilidad de su historización, es decir, a su fijación circunstancial que, por un lado permite abarcar no solo la lengua desde la cual se escribe, sino también y sobre todo, su potencial articulación convencional respecto de construir sus propias marcas como, a su vez, su distinción inequívoca que le hace ser literatura. En aquel sentido, para Cerda, las principales premisas que aparecen, por ejemplo en $E l$ grado cero de la escritura (2006) -entre ellas y como la más relevante la que indica que la escritura nace de la reflexión del escritor sobre el uso social de la forma- le abren una irrenunciable operación fabulatoria que no es ajena al talante político

\footnotetext{
${ }^{1}$ En conversación con el autor de este artículo, Gonzalo Geraldo Peláez uno de los organizadores durante 2013 del Seminario de Investigación Martín Cerda, indicaba de la publicación inminente en el transcurso del segundo semestre de 2014, de una serie de ensayos y artículos inéditos de Martín Cerda en Ediciones Universitarias de Valparaíso. Habrá que esperar que tal publicación sea efectiva, como asimismo la necesaria recopilación y publicación de los textos de Cerda publicados en diversos medios periodísticos y revistas de Venezuela en el transcurso de más de 20 ańos. Ello significará, sin duda, una reevaluación más pertinente de las diversas fuentes, impresiones e interpretaciones que Cerda, en tanto ensayista, haya efectuado tanto de la recepción de la obra de Roland Barthes y de muchos otros temas y autores por él abordados.
} 
que no es, sin más, que trazar una relación entre la escritura y la historia y cómo la primera nace de las circunstancias de la segunda. En esto, se trata de escrituras de definición, es decir, que valoran qué es el bien y el mal y juzgan de acuerdo a su posición. Esta manera de concebir la escritura nace también como un compromiso social, pero la autonomía de su forma es más grande en tanto que recibe una firma que borra la historia de la conversión del escribiente a ese compromiso y representa a la colectividad. Es justamente aquel talante el que es posible rastrear en Cerda cuando se refiere una y otra vez a la necesidad de fijar la escritura, el mismo talante que vemos en sus recorridos genealógicos buscando la razón de ser de la escritura ensayística (Cerda, 1982) como cuando asume, asimismo, la tensión que pueda haber entre compromiso y lenguaje, tensión que le llevará a reflexionar latamente sobre la deflación y aun el fracaso del discurso utópico $(1987 ; 2003)$, como a su vez, apreciar la fractura que, como sujeto de escritura, verá en la clausura de la ciudad letrada (1982). Bajo esas premisas, Barthes le otorga a Cerda no un mero estímulo de comprensión del fenómeno escrito, sino primordialmente, una invitación para evaluar de modo crítico las nociones positivistas de literatura y su más que evidente funcionalismo de apreciación ancillar que esta, en tanto discurso enraizado en un proceso identitario que ha hecho de la "raza" uno de sus axiomas fundacionales, posee de sus cultivadores y apologetas. Axiomas que la querella de 1954 muestra de modo ejemplar como un impasse ante la crisis de la representación a que la literatura chilena estaba arribando. Es por eso asimismo que Cerda, en un gesto apropiatorio y característico, toma también de Barthes la noción del ensayo como escritura ocasional que es, a su vez, la práctica secreta de lo "indirecto". Para eso, la referencia a la cual el autor chileno vuelve de modo permanente, será el "Prefacio" a los Ensayos Críticos del autor galo que, de modo ejemplificador, se asume como parte sustancial de una verdadera poética de la escritura ensayística que se encarna en la afanosa búsqueda que Cerda lleva a cabo en su libro La palabra quebrada (1982). El dictum de Barthes es decidor:

[...] el sentido de una obra (o de un texto) no puede hacerse solo; el autor nunca llega a producir más que presunciones de sentido, formas si se quiere, y el mundo es el que las llena. Todos los textos que se dan aquí son como eslabones de una cadena de sentidos, pero esta cadena es flotante. ¿Quién puede fijarla, darle un significado seguro? Quizás el tiempo: reunir textos antiguos en un libro nuevo es querer interrogar al tiempo, solicitar que nos dé su respuesta en fragmentos que proceden del pasado; pero el tiempo es doble, tiempo del escribir y tiempo de la memoria y esta duplicidad requiere a su vez un sentido siguiente: el tiempo mismo es una forma [...] lo que caracteriza al crítico es pues una práctica secreta de lo indirecto; para permanecer secreto, lo indirecto debe aquí ampararse bajo las figuras mismas de lo directo, de la transitividad, del discurso sobre otro (Barthes, 1983: 10-20). 
Este dictum barthesiano será fecundo en el ejercicio escritural de Cerda: le permitirá reflexionar sobre su propia escritura y le facilitará su justificación ante el inacabamiento de su gesto que tiende hacia lo fragmentario e indirecto como a su vez a volverse opaco para sí mismo y a poner en entredicho la presunta "claridad" expositiva que se requiere de la emergencia epocal que la literatura contingente exige del autor chileno. De ahí que la escritura de Cerda se vislumbre fragmentaria en la asunción del ensayo como género privilegiado de exposición y reflexión, como un singular género "ocasional" donde cada fragmento que lo constituye -notas, frases, auscultación de referentes culturales varios, remembranza de lugares antaño visitados, ensimismamiento con pedazos de biografía trunca y doliente, aforismos, comentarios, dilucidación de un posible sentido por medio de la celebración o el asombro electrizante- configura una totalidad respecto de sí misma y de un fantasmagórico y nunca existente libro, pero también y simultáneamente aquella totalidad permite advertir, en una fecunda ironía, que lleva dentro de sí la ausencia del todo, ausencia de la cual el ensayo forma, no obstante, una entidad acabada. En la escritura ensayística de Cerda ningún fragmento se basta a sí mismo: cada uno lleva en sí, por el contrario, lo que lo atrae hacia su recomienzo, hacia su infinita reiteración. Cada fragmento expresa y constituye, a la vez, un todo limitado y la ausencia de totalidad (Gavilán, 2013).

De aquel modo y en segundo término, es posible advertir entonces la necesidad de amplitud significante que Cerda requiere para su propia reflexión y que de modo inequívoco, vislumbra en otro texto de Barthes: Mitologías (2009). Sin duda que el punto de partida de esta obra es un sentimiento de impaciencia ante la apariencia de "naturalidad" con que la prensa, el arte y el sentido común, encubren permanentemente una realidad que no por ser la que vivimos deja de ser absolutamente histórica, ante la constante confusión entre naturaleza e historia en el relato de nuestra actualidad. Barthes pretende poner de manifiesto el abuso ideológico oculto en lo exposición decorativa de lo "evidente-por-sí-mismo", y lo hace recurriendo a la noción de mito para dar cuenta de esas falsas evidencias. Así, el mito es un lenguaje y, por ende, al ocuparse de hechos aparentemente alejados de toda literatura (un combate de catch, un plato de cocina, una exposición de plástica), Barthes explora otros tantos aspectos de esa semiología general del mundo burgués cuya vertiente literaria es el tema fundamental de la mayor parte de su obra (Giordano, 1995). En este sentido, no deja de ser relevante que Cerda, bajo aquella impronta, efectúe una verdadera fenomenología del acto de la escritura: varias de sus notas, apuntes y reflexiones, no tanto abordan un estilo aforístico en su brevedad contundente, sino que se asumen como partículas dejadas al paso para constituir una reflexión punzante y fragmentaria acerca de cosas y situaciones que lo vuelven un intenso calidoscopio crítico: sus referencias a las ciudades que añora y visita, su recurrencia a libros, datos, personajes y circunstancias, tejen en 
Cerda una red de referencias que van desde Marcuse a Vicuña Mackenna, desde las calles de Santiago de Chile a las de París, Viena o Caracas, desde la anécdota feliz de la circunstancia de un hotel pasajero, hasta la solemnidad melancólica de una evocación amorosa que tienen a Rilke y Kafka como telón de fondo. En esos textos breves, apuntes de lectura y apuntes de vida, -que en la imaginación verbal de Cerda este denomina, notas- asistimos no solo a un rapsódico narrar que se vuelve espasmódico, sino a una toma de pulso de las doxas que se suceden en el imaginario que teje su propia trama de sentido. Para Cerda, nuestra sociedad contemporánea inventa sus mitos en tanto mitos de lenguaje, mitos que se elevan a categorías autosuficientes y que su escritura ensayística se ve en la necesidad de auscultar y contradecir: el nacionalismo literario, la violencia social avalada por ciertas tendencias intelectuales, la tentación del nihilismo en la antesala de todo proceso revolucionario, la mudez a la que invita el suicidio, la ironía como rasgo esencial de la escritura. No pretendo, por supuesto dilucidar en su totalidad la rica consecuencia que para el ensayismo de Cerda ha traído su lectura de este pequeño, pero magistral libro de Barthes, pero sin duda su marca, su efigie, su seña, es identificable para indicarnos una manera de pensar y un modo de leer.

Finalmente y en tercer término hay un modo de entender la escritura que Cerda vislumbra en Barthes y que orienta una de sus últimas y más intensas reflexiones, aquel modo de entender la escritura en tanto escritura encarnada y que hace del cuerpo su punto de referencia ineludible. Glosando al Barthes final, al de El placer del texto y de Fragmentos de un discurso amoroso, Cerda efectúa una reflexión que hoy nos parecería normal, pero que dadas sus circunstancias históricas -mediados y fines de los años 80- forma parte de ese puñado de gestos reflexivos que una parte relevante de la intelectualidad chilena lleva a cabo desde la asunción especial de lo físico y corporal en la comprensión de los fenómenos culturales, estéticos y políticos (Richard, 2007). Para Cerda, en la estela del último Barthes, escribir es "dragar en el propio cuerpo", aun más, efectuar aquel ejercicio es registrar algo sustantivo y situado que, en su radicalidad enunciativa, implica preguntar sobre la desnudez, la enfermedad, el vestido, el deseo y el espectáculo. Es visualizar una posibilidad de la experiencia, ya clausurada por el silencio del significante en la exasperación de su mutilación social y que explica no solo la peculiaridad del comportamiento del sujeto -y en este caso de Barthes mismo- en relación a un círculo determinado de circunstancias epocales, si no más bien deja entrever un habla que hace alusión a la sociedad misma que le cobija, explota, admira y desea. Pero es también la seducción de un estilo ensayístico buscado y explorado, soportado y extendido, un estilo donde no hay continuidad, ni linealidad abrasadora bajo un concepto temporal unívoco, sino la aparición y desaparición de palabras y frases, en un gesto interpersonal de cercanía y alejamiento, una retórica cargada de erotismo que es la representación del eros mismo y donde la "duración" 
es el privilegio concedido a la escritura como interrupción, quiebre del espacio y, paradójicamente, como tiempo de la repetición, de la insistencia, convirtiendo a la escritura misma en un ademán circular que regresa a su origen como si en cierto modo nada hubiera acontecido salvo las palabras liberadas, anónimas y susurrantes. La desnudez del cuerpo, es la desnudez de las palabras en su gratuidad, pero también es la advertencia de su apariencia y su retórica de lo oculto y superficial, retórica bajo la que subyace ideología, espectáculo y, por ende, irredención. En ese sentido, no deja de ser decidor en el ensayismo de Cerda, cierto pudor admirativo hacia este último Barthes. Un pudor que implica distancia y también cierta admonición que se traduce en la afirmación trágica de su propio ensayismo. En todo caso, la recepción de Cerda es cualquier cosa, menos complaciente, pues como indicaba más arriba, su lectura de Barthes implicaba un aprendizaje en el camino de su propio pensar.

Solo deseo añadir como conclusión provisoria, una breve idea que me parece capital para entender, entre nosotros, la ordalía intelectual que ha implicado recepcionar a Roland Barthes y que ha tenido a Martín Cerda como uno de sus interlocutores subterráneos y excéntricos: frente a la imagen académica de Barthes como un "estructuralista" duro, hermético e inabordable -en curiosa analogía con la recepción ortodoxa de marxista infranqueable que el mundo académico nos ha otorgado de Georg Lukács- la aprehensión lectora fecunda y activa que Cerda nos otorga de él, nos lo devuelve como ensayista, como homme de lettres, como versátil escritor $y$, por tanto, como una sugestiva puerta de salida en el contexto de un discurso académico especializado: frente a la economía de riguroso calvinismo teórico -eficiencia demostrativa, economía léxica y asepsia subjetiva-Cerda, por medio de Barthes, nos invita, por un lado, a volver al ensayo como forma de escritura y, por otro, a dirigir la mirada con otros ojos al fascinante autor de tantos textos maravillosos, bellos, intensos y cuestionadores.

\section{REFERENCIAS}

Barthes, Roland. Ensayos criticos. Barcelona: Seix Barral, 1983.

El grado cero de la escritura. México: Siglo XXI, 2006. Mitologías. México: Siglo XXI, 2009.

Bernaschina, Vicente y Soto, Paulina. Crítica literaria chilena actual. Breve historia de debates y polémicas: de la querella del criollismo hasta el presente, 2011. Disponible en: http://www.historiacritica.cl. [Consultado el 30 de mayo de 2014]. 
Cerda, Martín. La palabra quebrada. Ensayo sobre el ensayo. Valparaíso: Ediciones Universitarias de Valparaíso, 1982.

Escritorio. Santiago, Chile: Galinost, 1987.

Palabras sobre palabras. Santiago, Chile: RIL, 2003.

Gavilán, Ismael. Martín Cerda: fragmentos de un mapa escritural. Una disposición pasajera Sexto Concurso de Ensayo en Humanidades (Ed.), Instituto de Humanidades - Universidad Diego Portales. Santiago, Chile: Ediciones Universidad Diego Portales (2013):171-214.

Giordano, Alberto. Roland Barthes. Literatura y poder. Rosario: Beatriz Viterbo Editora, 1995.

Hopenhayn, Martín. Ni apocalípticos ni integrados. Aventuras de la modernidad en América Latina. Santiago, Chile: Fondo de Cultura Económica, 2004.

Mariaca, Guillermo. El poder de la palabra. La crítica cultural hispanoamericana. Santiago, Chile: Tajamar, 2007.

Richard, Nelly. Márgenes e instituciones. Santiago, Chile: Metales Pesados, 2007.

Parra, Clara. La pugna secreta. Conformación del espacio de los estudios literarios hispanoamericanos. Bogotá: Ediciones Universidad Santo Tomás, 2013.

Subercaseaux, Bernardo. Historia de las ideas y de la cultura en Chile, Volumen 3 (1930-2001), Tomo 5. Política y Cultura, 2010. Disponible en: http://www. ideasyculturaenchile.cl. [Consultado el 30 de mayo de 2014]. 